\title{
An Investigation on a Pattern of Virtual Executive Stock Option Based on Multidimensional Performance Indices
}

\author{
Changzheng Zhang and Jiao Zhang* \\ School of Economics \& Management, Xi'an University of Technology, Xi'an, Shaanxi, 710054, China \\ ${ }^{*}$ Corresponding author
}

\begin{abstract}
Based on the limitations in practice of the executive stock option (ESO) in China, the paper proposes "a pattern of virtual ESO based on multidimensional performance indices" by integrating the advantages of the standardized patterns of the ESO in the western countries. The new pattern adopts the refined Black-Scholes Option Pricing Model and creates a "half-virtual ESO", which can improve the performance appraisal mechanisms, increase the reasonability of the option pricing, lower the cash constraints and promote the risk prevention of the abnormal volatility of the stock market.
\end{abstract}

Keywords—executive stock option; option pricing; virtual stock option; China; black-scholes option pricing model

\section{INTRODUCTION}

The executive stock option (ESO) in the western countries has produced rather mature patterns. Such patterns of the ESO have been proved by the practice to be effective in motivating the top executives, which are of irreplaceable contributions to the economic development of the western countries, especially the American. The good performing of such mature patterns needs the matching policy environment, the complete capital market and the perfect professional manager market. However, such conditions have not been realized in China at present. Accordingly, how to design a reasonable pattern of the ESO, which is not only more practical for the status quo of Chinese economic and policy environment, but confirming to the theoretical principles of the ESO to the greatest extent, is an unavoidable topic of great significance, both theoretical and practical.

At present, in the practices of the ESO in China, there have emerged various adaptive patterns of the ESO. To be specific, there are two categories of the patterns of the ESO.

The first is the patterns dominated by the government, which are represented mainly by the Shanghai Pattern, Wuhan Pattern, Beijing Pattern and Hangzhou Pattern ${ }^{[1][2][3]}$. The critical feature of such patterns is that such patterns of the ESO are taken in the charge of the government, and the design, execution and monitoring of such patterns are under the control of the government. That is to say, such patterns are of much richer administrative nature. According to the existing literature, such patterns have lowered the incentive effectiveness in the following aspects. First, the sources of the stock are limited by the existing laws; second, the standard degrees of the patterns are rather poor. For example, the method of option pricing, the executant of the option plan and the management authorities of the option are not reasonable or scientific; third, the performance evaluation mechanism is not perfect, which would lead to poor incentive effectiveness. For example, the performance indices are too limited, or there is a weak link between stock price and firm performance.

The second is the patterns dominated by the private sectors, which are represented by the Beijing Pattern, Sanmao Pattern and EVA virtual Patter, etc. The critical feature of such patterns is that they are designed and executed by the individual enterprises, and thus they are more exploratory and operable. Such patterns propose the plan of "virtual stock" by taking the Beijing Pattern as the blueprint, which can avoid the various legal obstacles and the volatility of the stock market. On the whole, such patterns are rather acceptable under the limitations of the existing imperfect capital market and laws. However, such patterns have lowered the incentive effectiveness of the ESO in the following three aspects. First, in order to afford the differences between the purchase price and exercise price of the virtual stock, the firms would have to produce a large amount of cash outflow, which would give great pressure on the cash flow of the firms. Second, when the volatility of the stock market is avoided by such patterns, the capital enlargement effect of the stock market would be avoided at the same time, which would decrease the incentive strength. Third, the option beneficiaries have never really owned the stock of the firms, which would weaken their psychological incentive effects.

\section{A PATTERN OF VIRTUAL ESO BASED ON MULTIDIMENSIONAL PERFORMANCE INDICES}

The four core components of the ESO are respectively the performance appraisal mechanism, the exercise schedule, the exercise price and the amount of the stock options. During the design process of an effective pattern of the ESO, the status quo of the four components naturally represents the pattern's critical features that can distinguish itself from the other patterns. The above-mentioned patterns of the ESO, e.g., "Beijing Pattern", "Wuhan Pattern" and "Shanghai Pattern", are all defined according to the differences in the four components. By comprehensively considering the experiences and failures of the practical patterns of the ESO, domestic or foreign, and further combing the state of the existing laws and the capital market, the paper proposes a pattern of virtual ESO based on multidimensional performance indices. 
There are three critical steps in this pattern. First, to set the value of options granted of the managers, which needs the perfect performance appraisal mechanism of the managers; Second, to determine the value of the option per share, which needs to clarify the specific virtual operation ways of the virtual stocks; Third, to grant the options to the managers and wait for the exercise.

\section{A. The Value of Options Granted}

The determination of the value of options granted faces two situations. One is the managers are granted when they are hired, the other is they accept the grant during their tenure. For the former situation, due to the absence of the problem of the performance appraisal, the firms can only determine the value of options granted by combining the price of the manager market and the bargaining results between the two sides. Such a situation is simple for the firms to deal with. What is more, this situation would soon change into the later situation, since the managers would be evaluated by the firms soon after their entering into the firms. For the later situation, the firms should make effective performance evaluation on the managers in order to identify the contributions of the managers during their tenure in the firms. And then the value of options granted can be determined.

Just as described by Keef and Roush (2003) $)^{[4]}$ and Keys et al. $(2001)^{[5]}$, EVA, as an emerging comprehensive performance evaluation method, is of great advantages in evaluating the top managers' performance. The most important thing is that EVA links the incentive indices of the top managers and the motives of the investors, i.e., the wealth increase, rather closely.

However, the shortcomings of the method of EVA are also obvious. First, the single index of EVA cannot measure the effort level and performance consequences of the top managers comprehensively. EVA is just an absolute index instead of the relative indices. For example, it does not consider the effect of firm size on the value of EVA. Therefore, the paper proposes another related index named EVPS (i.e., Economic Value Added Per Share). Second, the original purpose of the ESO is to link the evaluation of firm performance with the volatility of stock prices in the stock market. In this case, the top managers would be motivated to work hard for the interest maximization of the shareholders. Therefore, the price of the stock (PS), as a more comprehensive index of measuring firm performance, should be included into the indices system. Though the existing capital market even has not really reached the semi strong form mark(Gong-meng Chen et al., 2002; Chou and Lin, $2010)^{[6][7]}$, from a long-term perspective, PS actually can reflect the overall operation quality, development potentials and credit rating of the listed companies to a better degree. Finally, from the perspective of the psychological preferences of the investors, in order to ensure the confidence of the investors over the value preservation and appreciation of their investments, the other more direct measure is net asset value per share (APS).

When the firms determine the value of options granted, they can choose another more comprehensive performance appraisal indices and methods. For example, the popular method of Wall Ratio may be more comprehensive. However, such methods have limitations in making the shareholders and the managers understand the principles and requirements of the methods, which would lead to the managers feel confused when they make decisions. Besides, such methods are too complicated in practical operation, and the cost would be too high. The three indices chosen by the paper include the dynamic and static indices, the relative and the absolute indices, and the internal and external indices.

What needs to be explained here is that the performance indices proposed in this paper are just an example for designing the effective virtual patterns of the ESO. Such a performance indices system is far away from being satisfied. The focus of this paper is to provide an acceptable running pattern of the ESO in the sense of the whole. As for the other possible indices other than PS, the future studies can make more discussions. In a word, such a principle should be met when the indices are designed: in Chinese capital market, the performance appraisal of the firms should not depend completely on PS, and there must be some other corrective evaluation indices.

Under the evaluation mechanism of the multidimensional performance indices, the firms should determine the value of options granted to the managers according to the following steps. First, the managers and the listed companies consult the ratio of the value of options granted to EVA when the managers reach the expected performance objectives (r). Second, the firms evaluate the performance of the managers during the past period. And the completeness rate of each index is identified as rp, $\mathrm{rE}$ and $\mathrm{rA}$.

$$
\begin{gathered}
r_{P}=\left(P_{t-1}-P S_{t-1}^{\prime}\right) / P S_{t-1}^{\prime} \\
r_{\mathrm{E}}=\left(\text { EVAPS }_{\mathrm{t}-1}-\text { EVAPS }_{t-1}^{\prime}\right) / \text { EVAPS }_{t-1}^{\prime} \\
r_{\mathrm{A}}=\left(\mathrm{APS}_{\mathrm{t}-1}-\text { APS }_{\mathrm{t}-1}^{\prime}\right) / \text { APS }_{t-1}^{\prime}
\end{gathered}
$$

The listed companies should calculate the amount of the options granted to the managers with the weight coefficients which are defined according to the relative importance of each performance index indicated by the shareholders. The specific equation of the value of options granted to the managers is shown as Equation (4).

$$
Q=E V A_{t-1} \times r \times\left(1+r_{P} * \alpha+r_{E} * \beta+r_{A} * \gamma\right)
$$

The parameters in Equation (4) are explained as the follows: EVAt- 1 is the Economic Valued Added in the last year (t-1), while $r$ is the incentive coefficient co-determined by the firms and the managers. The other indicators are defined in Table 1.

TABLE I. THE CALCULATION PARAMETERS OF THE VALUE OF OPTIONS GRANTED TO THE MANAGERS

\begin{tabular}{|c|c|c|c|c|}
\hline Indicators & $\begin{array}{c}\text { Objective } \\
\text { value }\end{array}$ & $\begin{array}{c}\text { The realized } \\
\text { value }\end{array}$ & $\begin{array}{c}\text { Completeness } \\
\text { rates }\end{array}$ & $\begin{array}{c}\text { Weight } \\
\text { coefficient } \\
\mathrm{s}\end{array}$ \\
\hline PS & PS $_{\mathrm{t}-1}$ & PS $_{\mathrm{t}-1}$ & $\mathrm{rP}_{\mathrm{P}}$ & $\alpha$ \\
\hline EVAPS & EVAPS $_{\mathrm{t}-1}$ & EVAPS $_{\mathrm{t}-1}$ & $\mathrm{r}_{\mathrm{E}}$ & $\beta$ \\
\hline APS & APS $_{\mathrm{t}-1}$ & APS $_{\mathrm{t}-1}$ & $\mathrm{r}_{\mathrm{A}}$ & $\gamma$ \\
\hline
\end{tabular}




\section{B. The Determination of Options Price}

After the determination of the value of options granted, the next job is to set a reasonable price of the stock options in order to determine the actual amount of options granted to the managers. Among the pricing models of the ESO, there are respectively three most popular ones, respectively the Shelton Pricing Model(Shelton et al., 2005) ${ }^{[8]}$, Kassouf Pricing Model (Derming, 1997; Clifford and Smith, 1976) ${ }^{[9][10]}$ and Black-Scholes Option Pricing Model(B-S Model)(Foad and Tommi, 2017; Shoujun Huang et al., 2017) ${ }^{[11][12] .}$

The Shelton Pricing Model is the earlier model for pricing the stock options. Due to the great changes of the stock market's rules, the empirical formula would reach a too high value for the warrants with the longer maturity date, and what is more, the historical volatility of the stock's price has not been considered. The verification of the Shelton Model's effectiveness shows that the percentage of error for such a method is rather high. The cost of running the Kassouf Pricing Model is too high. And what is more, the variables involved in the calculation with the Kassouf Pricing Model are too many. The calculation process is too complicated. The B-S Model is delicate. Though the practical value of the B-S Model has been limited by the strict assumptions by the scholars, such a model can basically deal with the pricing needs of the normal options after minor adjustments. At the same time, the test results of the validity of the B-S Model are satisfied to a certain degree, especially when the interest has been modified. Therefore, in this paper, the B-S Model is applicable. The specific equation is shown as follows.

$$
\begin{gathered}
P=S N\left(d_{1}\right)-E e^{-r_{f} t} N\left(d_{2}\right) \\
\text { In Equation (5): } d_{1}=\frac{\ln (S / E)+r_{f} t+\sigma^{2} t / 2}{\sigma \sqrt{t}} \\
d_{2}=d_{1}-o \sqrt{t}
\end{gathered}
$$

$\mathrm{N}(\mathrm{d})$ : Under standard normal distribution, the probability of $\mathrm{X}<\mathrm{d}$ ( $\mathrm{X}$ is a random variable).

In a standard pricing model of stock options, E represents the exercise price, $S$ is the existing price of the stock, $\sigma$ is the volatility rate of the stock price, while rf is the risk-free rate of interest.

Such a standard pricing model of options cannot be applied directly in Chinese capital market, since the capital market of China has too weak effectiveness. The pricing design in this pattern considers the following facts.

First, when capital market is not valid, the stock price of the listed companies cannot exactly reflect the performance of the firms and the top managers, no matter for the Main-board or the Growth Enterprise Market in China. When the capital market faces the bubble territory, such a fact is especially prominent. For example, even when a manager has no good performance in running a firm, the increase of the whole capital market due to the macro economy or technical factors would make the firm's stock price get higher. However, even when a manager has excellent contributions in running a firm, the decrease of the whole capital market due to the bad macro factors would damage the firm's stock price. Therefore, such a incentive mode is not very objective.

Second, under the condition of immature stock market, the manipulation behavior on stock pricing by the critical investors usually occur. As we know, if the stock price is lower than the exercise price, the value of the stock options is zero. Therefore, the managers have the motivations to artificially raise the stock price by disclosing false information or even colluding with the securities companies. Hence such an incentive method would be distorted under this condition.

Based on the above considerations, the authors propose an incentive pattern of virtual stock options based on multidimensional performance indices. The multidimensional performance pattern indicates that stock price is not the only evaluation index, and the other evaluation indices can be introduced into the pattern according to the willingness of the shareholders, for example, EVAPS and APS. Here the proposed pattern adopts the concept of virtual stock. The so-called virtual stock indicates a kind of virtual value represented by certain amount of money decided by a series of factors, instead of the real "stock" of a firm. The core difference between the virtual stock option designed in this paper and the other virtual stock options mentioned the existing literature is that, when the managers exercise the options, the managers would get part of the real stock according to the amount of the income calculated based on the virtual stock options granted and the real stock price. As such, the managers would become the real shareholders and thus the long-term incentive and constrain of the managers would be realize effectively. At the same time, the cash flow would be saved to a large degree. Therefore, this pattern in the paper involves both the virtual stock and the real stock, which can be called as "semi-virtual" stock options.

According to the suggested performance indices in this paper, the three performance objectives of the managers designed by the shareholders are mainly PS, EVAPS and APS. Such three indices co-determine the price of the virtual stock. The virtual exercise price (E') and the current price of the virtual stock $\left(\mathrm{P}_{0}{ }^{\prime}\right)$ are respectively determined by the Equation (6) and Equation (7).

$$
\begin{aligned}
& E^{\prime}(P S, E V A P S, A P S)=\alpha * E+\beta * E \text { VAPS }_{t-1}+\gamma * A P S_{t-1} \\
& P_{0}^{\prime}(P S, E V A P S, A P S)=\alpha * P_{0}+\beta * \text { EVAPS }_{t-1}+\gamma * A P S_{t-1}
\end{aligned}
$$

The parameters in Equation (6) and Equation (7) are explained in Table 1. Hence the modified B-S Model can be described as Equation (8).

$$
P=P_{0}^{\prime} N\left(d_{1}\right)-E^{\prime} e^{-r_{f} t} N\left(d_{2}\right)
$$




$$
\begin{gathered}
\text { In Equation (8): } d_{1}=\frac{\ln \left(P_{0}^{\prime} / E^{\prime}\right)+r_{f} t+\sigma^{\prime 2} t / 2}{\sigma^{\prime} \sqrt{t}} \\
d_{2}=d_{1}-o^{\prime} \sqrt{t}
\end{gathered}
$$

\section{The Process Design of Realizing the Option Income}

Given $\mathrm{Q}$ in Equation (4)and $\mathrm{P}$ in Equation(8), the amount of options granted can be calculated by Equation(9).

$$
S=Q / P
$$

After a certain waiting period, the stock market would provide a comprehensive evaluation on firm performance, i.e., the stock price when the managers exercise the options $\left(\mathrm{P}_{1}\right)$, which is viewed as the result of the managers' contribution. According to Equation 7, we can turn $\mathrm{P}_{1}$ into the price of the virtual stock $\left(\mathrm{P}_{1}^{\prime}\right)$. Hence the option income of the managers when they exercise the options can be determined by Equation (10).

$$
R=S *\left(P_{1}^{\prime}-E^{\prime}\right)
$$

In the light of design of the other existing patterns of the virtual stock options, when it comes to this step, the firms can afford the income of options with the cash to the managers. However, as we know, the nature of the ESO is to make the managers run the firms from the perspective of the shareholders by equipping them with amount of the firms' stocks. On the other side, the most attracting point of the ESO is that the constraints on the cash flow of the firms would be removed by the ESO to a great extent. That is to say, the incentive cash is provided by the stock market, while the incentive effect is enjoyed by the firms. Otherwise, if the firms are required to afford the income of options with their cash-holdings, the pressures on the firms' cash flow are unacceptable, especially for the enterprises with rapid growth rate. Therefore, in this pattern, the running mechanism' core component of the popular ESO patterns in China is changed.

According to the logic of the pattern of the ESO in this paper, the standardized design principal of the international ESO pattern is followed, and the rights of purchasing the stock of the enterprises should be endowed to the managers when they exercise the options. The amount of the options granted to the mangers should be described as Equation (11).

$$
N=(1-\eta) * R / P_{1}
$$

In equation (11), $\eta$ represents the cash coefficient of the ESO, which can be decided by the managers to a large degree. However, the requirement of $\eta \leq 50 \%$ must be fulfilled. The remainder income of the options can be determined by the managers to abandon or change into stock.

\section{CONCLUSIONS}

The pattern of virtual ESO based on multidimensional performance indices have its specialized advantages in improving the performance appraisal mechanism of the listed companies, increasing the reasonability of the option pricing, lowering the constraint on cash flow and guarding against the risk of the abnormal volatility of the stock market.

(1) This pattern chooses the multidimensional performance indices which include both the external and internal indicators, the dynamic and static indicators, and the short-term and long-term indicators. Besides, the indices include EVAPS and APS, which can link the effort of the managers and the investors motivations closely. And the most important thing is that such indices cannot be manipulated by the managers with lower cost.

(2) On the pricing of the options, the pattern does not follow the popular pricing method of the international patterns due to limitations of policy and economic environment. To be specific, though the pattern selects the B-S Model as the pricing tool, the transformation of the "virtual stock" is executed to replace the variables in the B-S Model. Such a design can not only assure the reasonability, but consider the practical conditions of the capital market in China.

(3) The pattern in this paper has the advantage in preventing the abnormal volatility of the stock market and dealing with the incompleteness of the stock market. As we know, the risk of the stock market's deviation from firm performance can be expressed as $R_{1}=\operatorname{Var}\left(P_{0-t}\right)+\operatorname{Var}\left(P_{t+3}\right)$. Of which, $\operatorname{Var}\left(P_{0-t}\right)$ is the stock market's risk of performance deviation during the waiting period of the managers, while $\operatorname{Var}\left(P_{t+3}\right)$ is the stock market's risk of performance deviation after exercising the options. In the same logic, in this pattern the stock market's risk of performance deviation can be described as $R_{2}=\left(\frac{r_{P}}{r_{P}+r_{E}+r_{A}}\right)^{2} \operatorname{Var}\left(P_{0-t}\right)+\operatorname{Var}\left(P_{t+3}\right)$. Since the waiting period of the ESO is at least 4-5 years, with the stock market's getting mature, $\operatorname{Var}\left(P_{0-t}\right)>>\operatorname{Var}\left(P_{t+3}\right)$. It is obviously that $\mathrm{R}_{2}<\mathrm{R}_{1}$. Therefore, compared with the other normal patterns of the ESO, this pattern lowers the stock market's risk of performance deviation effectively. At the same time, the capital enlargement effect of the ESO is made a good use of.

(4) The pattern would not produce heavy pressures on the firms' cash flow. When the managers exercise the options, they would at most get the $50 \%$ of the cash income, the other parts of the income would have to be held as the stock for at least 4-5 years. As such, there would not be too heavy pressure on the firms' cash flow, and the managers would become the real "shareholders", whose interests are linked closely with the firms.

\section{ACKNOWLEDGMENT}

This research was supported by the Projects of the National Social Science Foundation of China under the Grant "15BGL109" 


\section{REFERENCES}

[1] Liu Xuning. Executive stock options: a review of related theories and their practical activities. Journal of Shandong Finance Institute, 2001(4):14-19. (in Chinese)

[2] Yu Yonghong. A study on the three modes of implementing executive stock option incentive in China and their comparison. Modernization of Management, 2000(5):30-32.

[3] Gao Jianbo. Investigation on the theory and practice of executive option incentive. Reform and Strategy, 2001(4):61-66.

[4] Keef S. P. and M. L. Roush. The Relationship Between Economic Value Added and Stock Market Performance: A Theoretical Analysis. Agribusiness, 2003, 19(2): 245-253.

[5] Keys D. E., M. Azamhuzjaev and J. Mackey. Economic Value Added: A Critical Analysis. The Journal of Corporate Accounting and Finance, 2001, 12(2): 65-71.

[6] Gong-meng Chen, Oliver Meng Rui and Steven Shuye Wang. The Effectiveness of Price Limits and Stock Characteristics: Evidence from the Shanghai and Shenzhen Stock Exchanges. Review of Quantitative Finance and Accounting, 2002, 25(2):159-182.

[7] Pai-Lung Chou and Jia-Jun Lin. Stochastic dominance and the momentum effect of the China's A-share market. Journal of Statistics and Management Systems, 2010,13(1): 179-197.

[8] Shelton Peiris, David Allen and Wenling Yang. Some statistical models for durations and an application to News Corporation stock prices. Mathematics and Computers in Simulation, 2005, 68(5): 545-552.

[9] Derming Lieu. Estimation of empirical pricing equations for foreign-currency options: Econometric models vs. arbitrage-free models. International Review of Economics \& Finance, 1997,6(3): 259-286.

[10] Clifford W. and Smith Jr. Option pricing: A review. Journal of Financial Economics, 1976,3, (1-2): 3-51.

[11] Foad Shokrollahi and Tommi Sottinen. Hedging in fractional BlackScholes model with transaction costs. Statistics \& Probability Letters, 2017,130(12): 85-91.

[12] Shoujun Huang, Jun Yang and Shanjun Li. Black-Scholes option pricing strategy and risk-averse coordination for designing vehicle-to-grid reserve contracts. Energy, 2017,137(15): 325-335. 